\title{
EVALUATION OF REACTANCES AND TIME CONSTANTS OF SYNCHRONOUS GENERATOR
}

\author{
Shaheena Khanum ${ }^{1}$, K.L Ratnakar ${ }^{2}$, Ramesh K.N ${ }^{3}$, Ravi.R ${ }^{4}$ \\ ${ }^{I} P G$ Student, Department of Electrical and Electronics Engineering, Sri Siddhartha Academy of Higher Education, \\ Tumkur, Karnataka, India \\ ${ }^{2}$ Professor, Department of Electrical and Electronics Engineering, Sri Siddhartha Academy of Higher Education \\ Tumkur, Karnataka, India \\ ${ }^{3}$ Quality Assurance, TD Power Systems Limited, Dabaspet, Bangalore, Karnataka, India \\ ${ }^{4}$ PG Student, Department of Electrical and Electronics Engineering, Sri Siddhartha Academy of Higher Education, \\ Tumkur, Karnataka, India
}

\begin{abstract}
For any power equipment the control system and protection system plays an imperative role as the dependency on the power equipment in any industry will be very high. Thus for the Generator the Reactances and Time Constants becomes controlling parameter and hence protecting it is necessary for prolonged usage. In general reactance shall be defined as "non-resistive component of impedance in an AC circuit, arising from the effect of inductance or capacitance or both and causing the current to be out of phase with the electromotive force causing it". In other word it can also be defined as the imaginary part of the impedance in any power circuit. There are various Reactances and Time Constants which contributes during the selection of control systems and protection scheme for any Generator. Therefore practical evaluation of those parameters shall also be super critical same as those are by calculation. More accurate measurement or the calculation of reactance shall certainly give us more stabilized error free system and hence ensuring a healthy control system. As there are different tests or different methods to measure and calculate the Reactances and Time Constants, in this context we are considering Line to Line fault ( L-L fault), Double line to Ground fault and Sudden three phase short circuit fault to determine the Negative Sequence reactance, Zero Sequence reactance, Sub-transient and Transient reactance and time constants respectively. The fault condition will be demonstrated with the 40MW, $11 \mathrm{KV}, 2624 \mathrm{~A}, 4$ pole, $50 \mathrm{~Hz}$ synchronous generator and above mentioned parameters are calculated based on references available.
\end{abstract}

Keywords: Reactances, Time Constants, Testing of Alternator, Brushless Alternator.

\section{INTRODUCTION}

The synchronous machine is an ac machine in which the rotor moves at a speed which bears a constant relationship to the frequency of currents, in the armature winding. A synchronous machine is one of the important types of electric machines. Large ac networks operating at constant frequency of $50 \mathrm{~Hz}$ or $60 \mathrm{~Hz}$ rely almost exclusively on synchronous generators, also called the alternators, for the supply of electrical energy, and may have synchronous compensators at key points for control of reactive power. Private stand-by and peak load plants with diesel or gas-turbine prime movers also have synchronous generators. Non-land-based synchronous plants are found on oil rings, on large air-crafts and constant speed industrial drives with the possibility of power factor correction, but are not often built in small ratings for which the induction motor is cheaper. Synchronous machines are generally constructed in larger sizes. Small size alternators are not economical. The modern trend is to build alternators of very large sizes capable of generating 500MVA or even more. An alternator works on the principle of Faraday's laws of Electro-Magnetic Induction.
"Whenever a conductor/coil cuts the magnetic flux an EMF is induced in that conductor. The magnitude of EMF induced in the conductor/coil is directly proportional to the rate of change of flux and the number of conductors". The main component which effects the operation of alternator is resistance and reactances. The effective resistance of the armature winding is somewhat greater than the conductor resistance, called the dc resistance, as measured by direct current. This is due to additional loss over the purely $\mathrm{I}^{2} \mathrm{R}$ loss, inside and sometimes outside the conductor, owing to alternating current. The main sources of this additional loss are

- Eddy current in the surrounding material,

- Magnetic hysteresis in the surrounding material and

- Eddy currents or unequal current distribution in the conductor itself.

In many cases it is sufficiently accurate to measure the armature resistance by direct current and increase it to a fictitious value, called the effective resistance, $R_{e}$ which is large enough to take care of these additional losses. Effective resistance, $\mathrm{R}_{\mathrm{e}}$ can vary widely from 1.25 to 1.75 or more times 
the dc resistance, depending upon design. The EMF setup due to armature reaction MMF $F_{a}$ is always in quadrature with the load current $I$ and is proportional to it. Thus it is equivalent to an EMF induced in an inductive coil and the effect of armature reaction can, therefore, be considered equivalent to reactance drop IX $X_{a}$ where $X_{a}$ is the fictitious reactance which takes care of the armature reaction effect. The armature winding possesses a certain leakage reactance $X_{l}$. The sum of leakage reactance $X_{l}$ and fictitious reactance $X_{a}$ is called the synchronous reactance.

\section{REACTANCES}

It can be defined as the imaginary part of the impedance in any power circuit. There are various Reactances and Time Constants which contribute during the selection of control systems and protection scheme for any Generator.

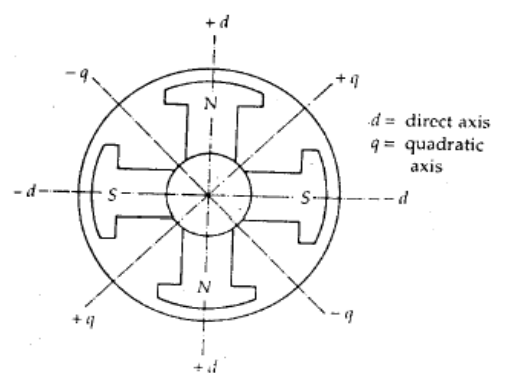

Fig -1: Axes of Alternator

The axis of symmetry of the north magnetic poles of the rotor is called the direct axis or d-axis. The axis of symmetry of the south magnetic poles is the negative d-axis. The axis of symmetry halfway between adjacent north and south poles is called the quadrature axis or q-axis.

- Direct axis reactance $\left(\mathbf{X}_{\mathrm{d}}\right)$ : The quotient of the sustained value of that fundamental $\mathrm{AC}$ component of armature voltage, which is produced by the total direct-axis primary flux due to direct-axis armature current and the value of the fundamental $\mathrm{AC}$ component of this current, the machine running at rated speed.

- Quadrature axis reactance $\left(\mathbf{X}_{\mathrm{q}}\right)$ : The quotient of the sustained value of that fundamental AC component of armature voltage, which is produced by the total quadratureaxis primary flux due to quadrature-axis armature current, and the value of the fundamental $\mathrm{AC}$ component of this current, the machine running at rated speed.

- Direct-axis transient reactance $\left(\mathbf{X}_{\mathbf{d}}{ }^{\prime}\right)$ : The quotient of the initial value of a sudden change in that fundamental AC component of armature voltage, which is produced by the total direct-axis primary flux, and the value of the simultaneous change in fundamental $\mathrm{AC}$ component of direct-axis armature current, the machine running at rated speed and the high decrement components during the first cycles being excluded.

- Direct axis sub-transient reactance $\left(\mathbf{X}_{\mathrm{d}}\right.$ "): The quotient of the initial value of a sudden change in that fundamental AC component of armature voltage, which is produced by the total direct-axis armature flux, and the value of the simultaneous change in fundamental $\mathrm{AC}$ component of direct-axis armature current, the machine running at rated speed.

- Negative sequence reactance $\left(\mathbf{X}_{2}\right)$ : The quotient of the reactive fundamental component of negative sequence armature voltage, due to the presence of fundamental negative sequence armature current at rated frequency, by the value of that component of current, the machine running at rated speed. - Zero sequence reactance $\left(\mathbf{X}_{\mathbf{o}}\right)$ : The quotient of the reactive fundamental component of zero sequence armature voltage, due to the presence of fundamental zero sequence armature current at rated frequency, by the value of that component of current, the machine running at rated speed.

\section{TIME CONSTANTS}

- Direct-axis transient short-circuit time constant $(\square \square$ d): It is the time, in seconds, required for the transient alternating component of the short-circuit current to decrease to $1 / \varepsilon_{0}$ or 0.368 times its initial value.

- Direct-axis sub-transient short-circuit time constant $(\square \square$ ):

It is the time, in seconds, required for the sub-transient alternating component of the short-circuit current to decrease to 0.368 times its initial value.

- Direct-axis transient open circuit time constant $\left(\square \square_{\text {do }}\right.$ ): It is the time, in seconds, required for the transient alternating component of the open-circuit current to decrease to 0.368 times its initial value.

\section{TESTING OF SYNCHRONOUS GENERATOR}

In this paper, study of different types of testing is going to be done for an alternator. Testing is the practice of making objective judgments regarding the extent to which the product meets else fails to meet the specified objectives. In other words for any manufactured product or equipments it is essential that the evaluation of the product with reference to the specification and the applicable standards. It is also indispensable for any manufacturer to ensure their product is meeting all the requirements as per their design and by their processes. Testing of a Generator or an Alternator also play a vital role before it is being put in to continuous operation. As the manufacturing of Generator involves various crucial processes either it may be carried by machinery or by man or may be both put together and hence it becomes important to assess the work done at the end. Though each component and part of the Generator has undergone various tests it is necessary that the complete assembled Generator also shall undergo at least Routine (described later) tests to understand the basic performance. [1]

Generator testing shall be of two types i.e. Type test and Routine test. Type test is inclusive of all routine tests along with some additional tests. Routine test is compulsory to 
understand the elementary performance of the Generators which comes under serial production type.

\subsection{Sudden Short Circuit Test}

\subsubsection{Circuit}

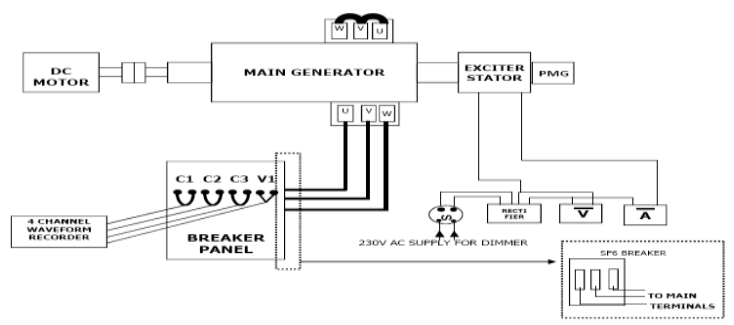

Fig-2: Sudden short circuit test setup

\subsubsection{Procedure}

1. Makes the connections as per the above diagram.

2. Run the generator to its rated speed.

3. Build up the voltage to $10 \%$ of the rated voltage.

4. Close the circuit breaker \& check the waveforms. Check the waveform for the Clear identification of the amplitudes. (Should be 3 current \& 1 voltage waveform)

5. If ok, then raise the voltage to $30 \%$ of the rated voltage then close the breaker, record the current and voltage waveforms.

6. Note down the steady state current, record \& print waveforms.

\subsection{Zero Sequence Test $\left(\mathrm{X}_{0}\right)$}

\subsubsection{Circuit}

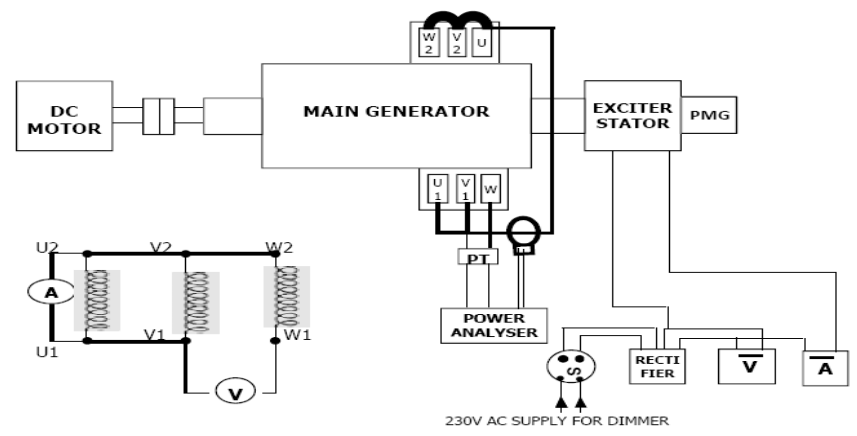

Fig-3: Zero sequence test setup

\subsubsection{Procedure}

1. Make the connections as per above circuit.

2. Run the machine to its rated speed

4. Record the values of current (I), voltage (V) and power.

5. $X_{0}$ shall be calculated using measured values.

3. Increase the armature current in steps of $10 \%, 20 \%, 30 \%$, $40 \%$ and $50 \%$ of rated current.

\subsection{Negative Sequence Test}

\subsubsection{Circuit}

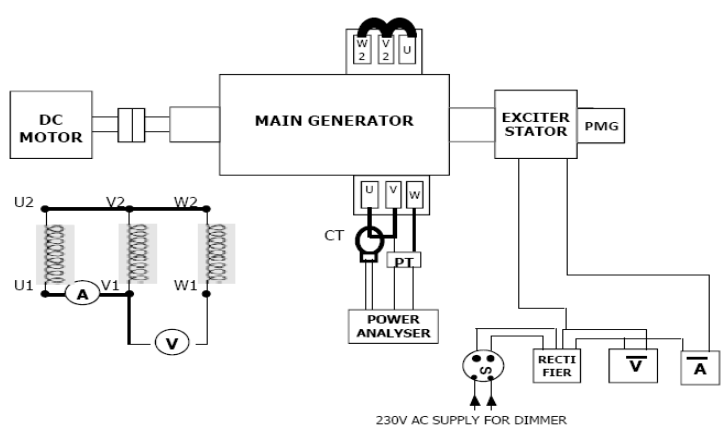

Fig-4: Negative sequence test setup

\subsubsection{Procedure}

1. Make the connections as per above circuit.

2. Run the machine to its rated speed

3. Increase the armature current in steps of $10 \%, 20 \%, 30 \%$, $40 \%$ and $50 \%$ of rated current.

4. Record the values of current (I), voltage (V) and power.

5. $\mathrm{X}_{2}$ shall be calculated using measured values.

\section{CALCULATIONS OF REACTANCES \& TIME} CONSTANTS

\subsection{Three Phase Sudden Short Circuit Test and Determination of Characteristic Reactance and Time Constants.}

The synchronous reactance $\left(\mathrm{X}_{\mathrm{d}}\right)$, transient reactance $\left(\mathrm{X}_{\mathrm{d}}^{\prime}\right)$ and sub-transient reactance $\left(\mathrm{X}_{\mathrm{d}}{ }_{\mathrm{d}}\right)$, and the transient short-circuit time constant $\left(\mathrm{t}_{\mathrm{d}}^{\prime}\right)$ and sub-transient short circuit time constant $\left(t^{\prime \prime}{ }_{d}\right)$ are used to describe and machine's behavior on sudden short-circuit. This can be done in accordance with the following equation for the AC RMS components of current following a three-phase short-circuit from no load neglecting armature-circuit resistances and assuming constant exciter voltage. [2]

$$
\mathbf{I}(\mathbf{t})=\left(\mathbf{E} / \mathbf{X}_{\mathrm{ds}}\right)+\left(\left(\mathbf{E} / \mathbf{X}_{\mathrm{d}}{ }^{\prime}\right)-\underset{\varepsilon^{\left(-t / \mathbf{T}_{\mathrm{ds}}{ }^{\prime}\right)}}{\left(\mathbf{E} / \mathbf{X}_{\mathrm{d}}\right)}\right) \varepsilon^{\left(-\mathrm{t} / \mathrm{T}{ }_{\mathrm{d}}{ }^{\prime}\right)}+\left(\mathbf{E} / \mathbf{X}_{\mathrm{d}}{ }^{\prime}-\mathbf{E} / \mathbf{X}^{\prime}{ }_{\mathrm{d}}\right)
$$

Where,

I ( $t)$ : is the AC RMS short- circuit current, p.u.

E: Is the AC RMS voltage before short circuit, p.u.

$\mathrm{t}$ : is the time in seconds, measured from the instant of short circuit.

In this expression, it is assumed that the current is composed of a constant term and two decaying exponential terms where the third term of the equation decays very much faster than the 
second. By subtracting the first (constant) term and plotting the remainder on semi-logarithmic paper as a function of time, the curve would appear as a straight line after the rapidly decaying term decreases to zero. The rapidly decaying portion of the curve is the sub-transient portion, while the straight line is the transient portion.

\subsection{Evaluation}

(a) Measure the voltage from wave form recorded (pk-pk) \& converts the same to RMS value

$$
E_{\mathrm{s}}=\mathrm{E}_{\mathrm{pk}-\mathrm{pk}} *(\mathrm{PT} \text { ratio }) /(2 * \operatorname{sqtr}(2))
$$

(b) Measure the $\mathrm{mV}$ drop of steady state current from the waveform recorded \& convert the same to amperes (RMS value)

$$
I_{\mathrm{s}}=\mathbf{m} V_{\text {pk-pk }} *(\text { Shunt ratio }) /(2 * \operatorname{sqtr}(2))
$$

(c) Peak to Peak value $(\mathrm{mV})$ of the currents from the waveform recorded is measured \& RMS value of the currents are calculated to first 50 to 60 cycles.

(d) Subtract the steady state current from point (c) \& plot the graph for the component currents $\left(\mathrm{I}_{\mathrm{k}}+\mathrm{I}_{\mathrm{k}}\right)$ in the semi log sheet with current in on log scale \& time on linear scale.

(e) To separate transient \& sub-transient components, extrapolation to zero time from the straight portion by neglecting the rapid variation of current in first few cycles will give the initial values of corresponding current. [7]

(f) From the semi log sheet

$\mathrm{I}_{\mathrm{k}}^{\prime}$ : is the AC RMS short-circuit transient current component in ampere (RMS).

$\mathrm{I}_{\mathrm{k}}$ : is the AC RMS short-circuit sub-transient current component in ampere (RMS).

$\mathrm{E}_{\mathrm{s}}$ : is the voltage before short circuit in RMS.

$\mathrm{I}_{\mathrm{s}}$ : is the AC RMS short-circuit steady state current in ampere (RMS).

\subsection{Determination of Direct Axis Sub-Transient}

\section{Reactance \& Short Circuit Time Constant $\left(\mathbf{X}_{\mathrm{d}}{ }^{\prime \prime} \&\right.$} $\left.\mathbf{T}_{\mathbf{d}}{ }^{\prime \prime}\right)$

To calculate $\mathrm{X}_{\mathrm{d}}$ " in \%

$$
X_{d}{ }^{\prime \prime} \text { in } \%=\left(E_{s} * 100\right) /\left(1.732 * Z_{s} *\left(I_{k}^{\prime}+I^{\prime \prime}{ }_{k}+I_{s}\right)\right)
$$

Where,

$\mathrm{Z}_{\mathrm{s}}(\Omega)$ : Synchronous impedance of the machine $=$ Rated Voltage / (1.732*Rated Current)

To calculate $\mathrm{T}_{\mathrm{d}}$ " in seconds

$\mathrm{T}_{\mathrm{d}}{ }^{\prime \prime}$ is the time required to decrease the sub-transient component to $1 /$ e i.e. 0.368 of its initial value.

OR Time for $\mathrm{I}_{\mathrm{d}}{ }^{\prime}$, where $\mathrm{I}_{\mathrm{d}}{ }^{\prime \prime}=0.368 * \mathrm{I}_{\mathrm{k}}$

\subsection{Determination of Direct Axis Transient Reactance}

\section{\& Short-Circuit Time Constant $\left(\mathbf{X}_{d^{\prime}} \& \mathbf{T}_{d^{\prime}}\right)$}

To calculate $X_{d}^{\prime}$ in $\%$

$$
\mathrm{X}_{\mathrm{d}} \text { in } \%=\left(\mathrm{E}_{\mathrm{s}} * 100\right) /\left(1.732 * \mathrm{Z}_{\mathrm{s}}^{*}\left(\mathbf{I}_{\mathrm{k}}^{\prime}+\mathbf{I}_{\mathrm{s}}\right)\right)
$$

Where,

$\mathrm{Z}_{\mathrm{s}}(\Omega)$ : Synchronous impedance of the machine $=$ Rated Voltage/(1.732*Rated Current)

To calculate $\mathrm{T}_{\mathrm{d}}$ ' in seconds

$\mathrm{T}_{\mathrm{d}}{ }^{\prime}$ is the time required to decrease the transient component to 1/e i.e. 0.368 of its initial value.

OR Time for $\mathrm{I}_{\mathrm{d}}{ }^{\prime}$, where $\mathrm{I}_{\mathrm{d}}{ }^{\prime}=0.368 * \mathrm{I}_{\mathrm{k}}{ }^{\prime}$

\subsection{Determination of Direct Axis Synchronous}

\section{Reactance $\left(\mathbf{X}_{\mathrm{d}}\right)$}

To calculate $X_{d}$ in \%

$$
\mathrm{X}_{\mathrm{d}} \text { in } \%=(\mathbf{1} / \mathrm{SCR}) * 100
$$

Where, SCR: Short circuit ratio of the machine

$$
\operatorname{SCR}=\left(\mathbf{I}_{\text {foc }} / \mathbf{I}_{\text {fsc }}\right)
$$

$\mathbf{I}_{\text {foc }}$ : Field Current for rated voltage.

$\mathbf{I}_{\text {fsc }}$ : Field Current for rated current.

\subsection{Determination of Direct Axis Transient Open}

\section{Circuit Time constant $\left(\mathbf{T}_{\mathrm{do}}{ }^{\prime}\right)$}

To calculate $\mathrm{T}_{\mathrm{do}}$ ' in seconds

$$
\mathbf{T}_{\mathrm{do}}{ }^{\prime} \text { in seconds }=\left(\mathbf{X}_{\mathrm{d}} * \mathbf{T}_{\mathrm{d}}{ }^{\prime} / \mathbf{X}_{\mathrm{d}}{ }^{\prime}\right)
$$

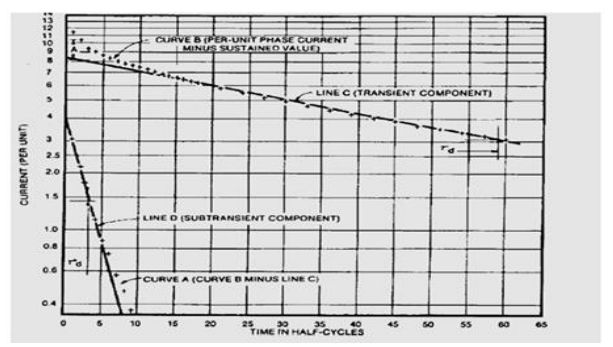

Fig-5: Analysis of ac component of short-circuit current (for one of three phases )

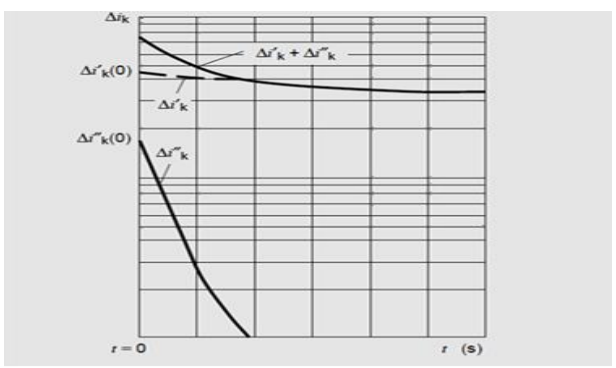

Fig-6: Transient \& Sub-transien component of short-circuit 


\section{EXPERIMENTAL RESULTS}

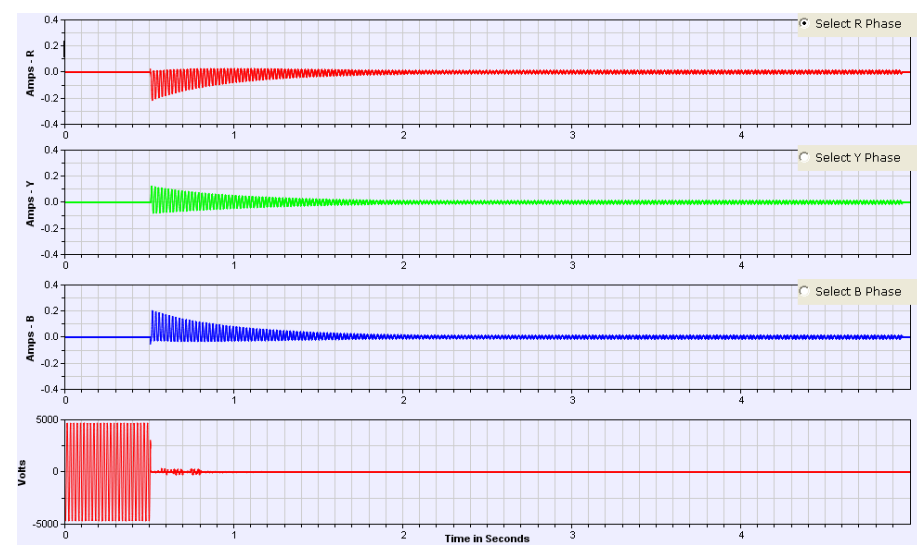

Fig-7: Voltage and Current Waveforms

Table- 1: Values of Reactances

\begin{tabular}{|l|l|l|}
\hline Reactances & $\begin{array}{l}\text { Design } \\
\text { value(\%) }\end{array}$ & $\begin{array}{l}\text { Calculated } \\
\text { value }(\%)\end{array}$ \\
\hline Xd & 166 & 161.3 \\
\hline Xd' & 29 & 30.7 \\
\hline Xd'' & 23 & 25.2 \\
\hline X2 & 30 & 30.08 \\
\hline X0 & 17 & 18.15 \\
\hline
\end{tabular}

Table- 2: Values of Time Constants

\begin{tabular}{|l|l|l|}
\hline Time Constants & $\begin{array}{l}\text { Design } \\
\text { value(sec) }\end{array}$ & $\begin{array}{l}\text { Calculated value } \\
(\mathrm{sec})\end{array}$ \\
\hline Td' & 0.82 & 0.84 \\
\hline Td' & 0.035 & 0.035 \\
\hline Td0' & 4.69 & 4.408 \\
\hline
\end{tabular}

As per the IEEE standards used the acceptable tolerance allowed is $\pm 15 \%$ or $30 \%$ on one side.

\section{CONCLUSIONS}

The above procedure and the calculation shall be used as a generalized method for calculation of Transient, sub-transient reactance $\mathrm{X}_{2}, \mathrm{X}_{0}$ and Time Constants for both cylindrical and salient pole type alternator of any rating. Though the Transient behavior involves tedious steps of calculation and deep analysis of the results, the above procedure helps in calculating the various parameters in easiest way with minimum calculation and time.

\section{ACKNOWLEDGEMENTS}

The authors express their sincere thanks to Dr. B. Rajesh Kamath, B.E., M.E., Ph.D., FIE., MISTE Head of the Dept. E\&EE, SSIT, Tumkur for his many helpful suggestions.

\section{REFERENCES}

[1]. IEEE115 standards for "Test procedure for synchronous machines".

[2]. IEC60034 "Methods for determining synchronous machine quantities from tests".

[3]. Marxsen, A. L. and Morsztyn, K., "Analysis of Synchronous Machine Transient Tests Using a Microcomputer," Proceedings IEE, 124(4), pp. 377-380, 1977.

[4]. C.Grantham, D. Sutanto, and B. M ismail, "Steady-state and transient analysis of self-excited induction generators," Proc Inst. Electrical Eng. B, vol. 136, no. 2, pp. 61-68, 1989.

[5]. R. Leidhold, G. Garcia, and M. I. Valla, "Field-oriented controlled induction generator with loss minimization," IEEE Trans. Ind. Electron., vol. 49, pp. 147-155, Feb. 2002.

[6]. Canay, I. M., "Causes of Discrepancies on Calculation of Rotor Quantities and Exact Equivalent Diagrams of the Synchronous Machine," IEEE Transactions on Power Apparatus and Systems, vol. PAS-88, pp. 1114-1120, July 1969.

[7]. "THE TRANSIENT REACTIONS OF ALTERNATORS" by William A Durgin and R. H. Whitehead, a paper to be presented at the 29th annual convention of the America Institute of Electrical Engineers, Boston, Mass., June 28, 1912.

[8]. "TRANSIENT PERFORMANCE OF THREE-PHASE INDUCTOR-TYPE SYNCHRONOUS GENERATORS: PAPER I- SYMMETRICAL SHORT CIRCUIT" By P.K. Dash, Regional Engineering College, Rourkele-8, Orissa, India.

[9]. Coultes, M. E. and Watson, W., "Synchronous Machine Models by Standstill Frequency Response Tests," IEEE Transactions on Power Apparatus and Systems, vol. PAS-100, no. 4, pp. 1480-1489, April 1981.

[10]. "Determination of Synchronous Machine Stability Study Constants"-EPRI Report EL 1424, vol. 1, Sept. 1980, Westinghouse Electric Corporation and vol. 2, Dec. 1980, Ontario Hydro. [Two of four reports on EPRI Project 997.] 